\title{
Genetic variation in a continuously breeding population of Danaus plexippus $L$.: an examination of heterozygosity at four loci in relation to activity times
}

\author{
Patrick A. Carter, ${ }^{*} \ddagger$ \\ Jane M. Hughes, ${ }^{*}$ and \\ Myron P. Zalucki†
}

\author{
* School of Australian Environmental Studies, \\ Griffith University, Queensland 4111, Australia. \\ $\dagger$ Department of Entomology, University of \\ Queensland, St. Lucia, Queensland 4067, Australia.
}

A population of Monarch butterflies was sampled at different times of the day on seven separate occasions. Four polymorphic loci (Pgi, Pgm, Idh and $\mathrm{Hbdh}$ ) were examined and heterozygosity levels were compared between early and late fliers. For both Pgi and Pgm significantly higher frequencies of heterozygotes were caught early in the morning indicating that heterozygotes were active earlier in the day than homozygotes. A separate experiment confirmed that there were no differences between homozygotes and heterozygotes in activity later in the day. No consistent relationship was found for the other two loci. The possibility that selection may be acting at the Pgi and Pgm loci is discussed.

\section{INTRODUCTION}

Hughes and Zalucki (1984) and Zalucki et al. (1987) reported on a long term study of genetic variation in continuously breeding populations of Monarch butterflies, Danaus plexippus, in southeast Queensland, Australia. Both studies recorded spatial differences in genetic variation of Monarchs, although the level of variability was lower in the second study. The second study reported some influence of weather, and possibly time of day, on genotype frequencies in these butterflies. We suggested (Zalucki et al. 1987) that if different genotypes are active at different times of day, then between locality variation would appear to be higher than it truly is, because of biases introduced by the time at which a sample was taken. Indeed, Watt et al. (1983), who showed activity time differences among Pgi genotypes in Colias butterflies, warned that activity time differences, if not identified, could lead to a misinterpretation of the genetic structure of a population. We also showed that Monarchs are not selecting habitats as a function of genotype (Zalucki et al., 1987), which again indicates that the spatial differences in genetic variation may be an artifact of sampling technique.

$\$$ Present Address: Department of EPO Biology, University of Colorado, Colorado 80309, U.S.A.
Activity time differences between genotypes are themselves of interest. An ectotherm, such as a butterfly, is dependent on environmental conditions, especially temperature, for its activity. Activity time differences between genotypes in monarch butterflies would raise the possibility that selection might be acting at the loci in question. In fact, Watt (1977), and Watt et al. (1983 and 1985) have shown that daily activity differences play a major role in natural selection acting at the $P g i$ locus in Colias butterflies.

In an attempt to identify underlying causes of previously reported spatial differences, and to look for differences in activity time in relation to possible selective effects, we examined the effects of time of day on heterozygosity levels at four polymorphic loci (Pgm, Idh, Hbdh and Pgi) in Monarch butterflies. Three of these loci, Pgm, Idh, and $H b d h$, were examined in the previous studies, and Pgi is added here.

\section{MATERIALS AND METHODS}

All experiments were condıcted at Mt Crosby $\left(152^{\circ} 48^{\prime} 30^{\prime \prime} \mathrm{E} ; 27^{\circ} 31^{\prime} 30^{\prime \prime} \mathrm{S}\right) \mathrm{ca} .17 \mathrm{~km}$ west-southwest of Brisbane, Australia. Butterflies were collected over a large area ( $c a .110,000$ sq. m), consisting of thick patches of milkweed (Asclepias fruticosa) interspersed with areas of scattered milkweed $(\boldsymbol{A}$. 
fruticosa, and A. curassavica) among various grasses, adjacent to a creek. The collecting area lay between contours 60 and $80 \mathrm{~m}$. Areas above $80 \mathrm{~m}$ elevation were covered by dry sclerophyll forest. The creek was also lined with various shrubs and clumps of lantana.

On all collecting days we arrived at the site by sunrise. The first collecting period lasted for 1 hour after the first butterfly was seen to make a sustained voluntary flight. Only voluntarily flying butterflies were netted. The second and third collecting period followed after a $\frac{1}{2}-1$ hour break. During the second (and subsequent) netting period all butterflies seen were netted. Temperatures in second (and subsequent) periods exceeded flight threshold ( $c a$. $15^{\circ} \mathrm{C}$, Masters, in press; Alonso et al. in press) and it is reasonable to assume that all animals had been and could be active. For the purposes of this paper we classified collections as early (the first period) or late (all subsequent collections). To ensure a large sample and coverage of the site during each capture period, at least 3 (usually 5) collectors were present. Despite the large sampling effort the area was sufficiently large and the population of monarchs large enough to approximate sampling with replacement. A mark-recapture estimate made between 29 November 1985 to 5 December 1985, indicated that we were only removing between 7-11 per cent of monarchs in each sampling period. Air temperatures were monitored regularly throughout each experiment.

As part of another study, we conducted an extensive mark/recapture experiment to compare the consistency of the timing of activity across days. To test if activity per se differs between heterozygotes and homozygotes in late sample periods we present some results of this experiment here (Hughes, Zalucki, Carter and Arthur, in preparation). Samples were collected in the same manner as outlined above, except all animals in late samples were classified into activity categories before capture viz; inactive: feeding, basking, resting; and active: flying, mating. For late samples we compared activity in relation to heterozygosity at the four loci using a three-way log-linear analysis.

Individuals were killed by severing the ventral nerve cord. The abdomen was immediately homogenized, centrifuged, and the supernatant electrophoresed on Titan III cellulose acetate plates (Helena Laboratories) and genotyped for $P g m, I d h$, and $H b d h$ in the manner described by Hughes and Zalucki (1984) and Zalucki et al. (1987). Individuals were genotyped for Pgi on the Pgm plates, since the two loci stain on separate portions of the plate, by adding to the Pgm staining solution $0.002 \mathrm{M}$ fructose-6-phosphate. Hierarchical log-linear analysis was used to examine the effects of sampling day and time of day on heterozygote frequency. Data were analyzed using the SPSS statistical package on the University of Colorado VAX cluster computer.

\section{RESULTS}

$P g m, P g i$, and $I d h$ were all plymorphic with three alleles present, designated slow (S), medium (M) and fast (F) according to electrophoretic mobility at each locus. Hbdh had two alleles present, slow (S) and fast (F). At each locus, the expected banding patterns were observed, i.e., Pgi, $\mathrm{Hbdh}$ and $\mathrm{Idh}$ showed patterns consistent with dimers, and Pgm showed a pattern consistent with a monomer.

The genotype of each locus for each individual was scored as either a heterozygote or a homozygote, and the numbers of heterozygotes and homozygotes for each time of each sampling day were calculated (table 1). There was a higher frequency of heterozygotes in the morning on seven of seven sampling days for $P g m$, on five of seven sampling days for $P g i$, on four of seven sampling days for $H b d h$, and on two of seven sampling days for Idh.

Both Pgi and Pgm show a significant interaction between heterozygosity and time of day (table 2). Two possible hypotheses might account

Table 1 Frequency $(f)$ of heterozygotes at the $\mathrm{Pgm}, \mathrm{Pgi}, \mathrm{Hbdh}$ and $I d h$ loci as a function of day and time of day collected. Sample size $(n)$ is provided for each day and time at each locus. Statistical analysis of these data is presented in table 2

\begin{tabular}{|c|c|c|c|c|c|c|c|c|c|}
\hline \multirow[b]{2}{*}{ Date } & \multirow[b]{2}{*}{ Time } & \multicolumn{2}{|l|}{$P g m$} & \multicolumn{2}{|l|}{$P g i$} & \multicolumn{2}{|c|}{ Hbdh } & \multicolumn{2}{|l|}{$I d h$} \\
\hline & & $f$ & $n$ & $f$ & $n$ & $f$ & $n$ & $f$ & $n$ \\
\hline \multirow[t]{2}{*}{$4 / 85$} & early & 0.57 & 49 & 0.63 & 49 & 0.26 & 49 & 0.12 & 49 \\
\hline & late & 0.49 & 49 & 0.50 & 50 & 0.32 & 50 & 0.20 & 49 \\
\hline \multirow[t]{2}{*}{$6 / 85$} & early & 0.66 & 38 & 0.55 & 42 & 0.38 & 42 & 0.05 & 42 \\
\hline & late & 0.59 & 66 & 0.46 & 70 & 0.36 & 74 & 0.27 & 70 \\
\hline \multirow[t]{2}{*}{$12 / 85$} & early & 0.70 & 147 & 0.74 & 113 & 0.37 & 158 & 0.28 & 160 \\
\hline & late & 0.63 & 135 & 0.54 & 132 & 0.38 & 143 & $0 \cdot 18$ & 142 \\
\hline \multirow[t]{2}{*}{$6 / 86$} & early & 0.77 & 22 & 0.57 & 21 & 0.41 & 22 & 0.32 & 22 \\
\hline & late & 0.70 & 30 & 0.62 & 32 & 0.38 & 32 & 0.41 & 32 \\
\hline \multirow[t]{2}{*}{$8 / 86$} & early & 0.79 & 24 & 0.57 & 21 & 0.39 & 23 & 0.38 & 24 \\
\hline & late & 0.62 & 39 & 0.63 & 35 & 0.34 & 35 & $0 \cdot 26$ & 39 \\
\hline \multirow[t]{2}{*}{$9 / 86$} & early & 0.64 & 33 & 0.66 & 36 & 0.54 & 35 & 0.36 & 36 \\
\hline & late & 0.54 & 55 & 0.57 & 58 & 0.45 & 56 & 0.53 & 58 \\
\hline \multirow[t]{2}{*}{$10 / 86$} & early & 0.71 & 38 & 0.72 & 47 & 0.27 & 45 & 0.30 & 46 \\
\hline & late & 0.66 & 41 & 0.66 & 56 & 0.40 & 55 & 0.33 & 55 \\
\hline
\end{tabular}


Table 2 Results of the log-linear analysis examining interactions between heterozygosity (Het), time of day (Time) and day of sampling (Day). Each locus was analysed separately and only significant interactions $(P<0.05)$ are shown

\begin{tabular}{lll}
\hline Locus & Significant interaction & Level of significance \\
\hline$P g m$ & Day $\times$ Time & 0.038 \\
& Time $\times$ Het & 0.019 \\
\hline$P g i$ & Time $\times$ Het & 0.002 \\
\hline$H b d h$ & Day $\times$ Het. & 0.044 \\
\hline$I d h$ & Day $\times$ Time $\times$ Het. & 0.004 \\
\hline
\end{tabular}

for this pattern. Either Pgi and Pgm heterozygotes are more likely to be active early (at low temperatures) or heterozygotes at these loci are generally more active, and the result represents an artifact of sampling since we netted only active animals early and all animals regardless of activity in late samples. The relationship between activity and heterozygosity is shown for late samples in table 3. In no locus was there a significant interaction between heterozygote frequency and activity in late samples $(P>0.05)$ (See table 3$)$.

Time of day affects heterozygosity levels, and there are more heterozygotes flying in the morning than later in the day at both Pgi and Pgm loci. There are no consistent deviations from HardyWeinberg equilibrium at either of these loci, so levels of heterozygosity are changing with changes in allelic frequency.

$H b d h$ does not have a significant heterozygote by time of day interaction term; thus heterozygote levels are independent of time of day at this locus. $I d h$ has a significant three-way interaction indicating that there is no consistent effect of time of day

Table 3 Frequency $(f)$ of heterozygotes at the Pgm, Pgi, Idh and $H b d h$ loci as a function of activity (A: Active, I: Inactive) on 3 days for samples taken after the initial sampling period

\begin{tabular}{llllllll}
\hline & & \multicolumn{2}{c}{ Day 1 } & \multicolumn{2}{c}{ Day 2 } & \multicolumn{2}{c}{ Day 3 } \\
Locus & Activity & $f$ & $n$ & $f$ & $n$ & $f$ & $n$ \\
\hline Pgm & A & 0.57 & 14 & 0.65 & 26 & 0.66 & 50 \\
& I & 0.56 & 16 & 0.77 & 13 & 0.61 & 46 \\
Pgi & A & 0.80 & 15 & 0.76 & 25 & 0.78 & 54 \\
& I & 0.63 & 16 & 0.46 & 13 & 0.73 & 58 \\
Idh & A & 0.27 & 15 & 0.38 & 26 & 0.27 & 52 \\
& I & 0.56 & 16 & 0.38 & 13 & 0.36 & 47 \\
Hbdh & A & 0.15 & 15 & 0.15 & 26 & 0.25 & 52 \\
& I & 0.19 & 16 & 0.38 & 13 & 0.27 & 48 \\
\hline
\end{tabular}

on heterozygote frequency and that the relationship between time of day and heterozygote frequency varies between sampling days.

\section{DISCUSSION}

For the Pgi and Pgm loci, there is a relationship between time of day and frequency of heterozygotes flying, such that a larger proportion of the population flying in the early morning are heterozygotes. We can discount heterozygoes being generally more active at all times (table 3 ). In most cases, the absolute numbers of heterozygotes increase from early to late; thus it is an increase in homozygotes flying later which causes the decrease in frequency of heterozygotes flying later in the day. This in turn means that the heterozygotes are getting up earlier and flying longer through the course of the day than the homozygotes.

Recent studies reviewing life table work on Lepidoptera (Dempster, 1983; Shapiro, 1986) indicate that the key factor limiting population increase is the inability of females to lay their egg complement. This limitation is by adverse weather conditions limiting the amount of time in a day that adults can be active. This suggests that there should be strong selection favouring any genotypes that become active earlier in the day especially if this means they can be active under a wider range of weather conditions.

As we have pointed out, this result makes our previously reported locality variation appear to be higher than it really is (Zalucki et al., 1987). Thus our earlier results can be explained in part by differences in activity times.

These differences in daily activity times also raise the possibility of functional differences between allozymes produced by the Pgi and Pgm genes. Watt $(1977,1983)$ found that functional differences between Pgi allozymes explained observed differences in activity times between $P g i$ genotypes in Colias butterflies. (It is interesting to note that Carter and Watt (1988) did not find daily activity time differences between Pgm genotypes in Colias). Furthermore, Watt (1977), Watt et al. (1983), (1985) and (1986) demonstrated how the observed differences in activity times between $P g i$ genotypes in Colias resulted in increased survivorship for Pgi heterozygotes and increased male mating success for male Pgi heterozygotes. The results reported here suggest that similar studies in the continuously breeding populations in monarchs in Queenslands would be of interest. 
Acknowledgements We thank Jeff Mitton, for critical insight into the data, and Allen Moore for an introduction to log-linear analysis. We also wish to thank the following people who helped with field collection: Debra Harrison, Manon Griffiths, Chris Hill, Peter Mather, Brad Congdon, Ian Williamson, Graeme Backholm and Paula Coutts. The project was supported by grants to Jane Hughes and Myron Zalucki from the Australian Research Grants Scherne and the Griffith University Research Fund.

\section{REFERENCES}

ALONSO, A. M., ANDERSON, J. A., GLENDINNING, J. I. AND BROWER, L. P. 1989. Shivering behaviour as an important factor in rate of crawling for survival of grounded overwintering Monarch butterflies, Danaus plenippus (L.), in Mexico-Ihid (In press).

CARTER, P. A. AND WATT, W. B. 1988. Adaptation at specific loci. V. metabolically adjacent enzyme loci may have very distinct experiences of selective pressures. Genetics, 119 , 913-924.

DEMPSTER, J. P., 1983. The natural control of populations of butterflies and moths. Biol. Rev., 58 461-481.

HUGHES, J. M. AND ZALUCKI, M. P. 1984. Genetic variation in a continuously breeding population of Danaus plexippus L. (Lepidoptera: Nymphalidae). Heredity, 52, 1-7.
MASTERS, A. R. 1989. The importance of temperature and thermoregulation to the Monarch butterfly, Danaus plexippus (L.). In Malcolm, S. B. and Zalucki, M. P. (eds) The Biology and Conservation of the Monarch Butterfly, National History Museum of Los Angeles Contribution to Science (In press).

SHAPIRO, A. M. 1986. $\mathrm{r}-\mathrm{K}$ selection at various taxonomic levels in the pierine butterflies of North and South America. In Taylor, F. and Karban, R. (eds) The Evolution of Insect Life Cyles, Springer-Verlag, New York.

WATI, W. B. 1977. Adaptation at specific loci. I. Natural selection on phosphoglucose isomerase of Colias butterflies: biochemical and population aspects. Genetics, 87 177-194.

WATT, W. B. 1983. Adaptation at specific loci. II. Demographic and biochemical elements in the maintenance of the Colias Pgi polymorphism. Genetics, 103, 691-724.

WATT, W. B., CARTER, P. A. AND BLOWER, S. M. 1985. Adaptation at specific loci. IV. Differential mating success among glycolytic allozyme genotypes of Colias butterflies. Genetics, 109, 157-175.

WATT, W. B., CARTER, P. A. AND DONOHUE, K. 1986. Females' choice of "good genotypes" as mates is promoted by an insect mating system. Science, 233, 1187-1190.

WATT, W. B. CASSIN, R. C. AND SWAN, M. S. 1983. Adaptation at specific loci. III. Field behavior and survivorship differences among Colias Pgi genotypes are predictabie from in vitro biochemistry. Genetics, 103, 725-739.

ZALUCKI, M. P., HUGHES, J. M. AND CARTFR, P. A. 1987. Genetic variation in Danaus plexippus L. Habitat selection of differences in activity times? Heredity, 59, 213-221. 